\title{
New Generation Anticonvulsants for the Treatment of Epilepsy in Children
}

\author{
Elizabeth J. Donner and O. Carter Snead III \\ Division of Neurology and Program in Brain and Behavior, Hospital for Sick Children, Department of Pediatrics, Faculty of \\ Medicine, University of Toronto, MSG 1 X8 Toronto, Ontario, Canada
}

Summary: In the last 12 years, 10 new anticonvulsants have been approved by the U.S. Food and Drug Administration and, as a result, the treatment options for children and adults with epilepsy have been expanded considerably. These new generation antiepileptic drugs offer equal efficacy with improved tolerability, pharmacokinetic properties, and side effect profiles compared with the traditional drugs. With many new medica- tions available, the clinician treating children with epilepsy must be well versed in the application of these drugs to their patient population. This manuscript will review the indications, mechanism of action, pharmacokinetics, adverse effects, and dosing of the new generation of anticonvulsant medications. Key Words: Antiepileptic drug (AED), anticonvulsant, epilepsy, children.

\section{INTRODUCTION}

Epilepsy is a chronic condition characterized by recurrent unprovoked seizures. Affecting almost 2 million people in the United States, the greatest incidence of epilepsy is in young children and the elderly. ${ }^{1}$ While the goal of epilepsy management is complete control of seizures with little or no adverse effects, only about $60 \%$ of patients become seizure free with treatment with a single antiepileptic drug (AED). Approximately 35\% of patients will continue to have seizures despite treatment with one or more AED. ${ }^{2}$

Before 1993, the drugs available to physicians who care for children with epilepsy were phenobarbital, phenytoin, carbamazepine, valproic acid, ethosuximide, and the benzodiazepines. In the last 12 years, 10 new AEDs have been approved by the U.S. Food and Drug Administration (FDA) and, as a result, the treatment options for children and adults with epilepsy have been expanded considerably (FIG. 1, Table 1).

The advent of the new AEDs has been encouraged by the suboptimal performance of the traditional AEDs, with many patients left with ongoing seizures and intolerable side effects. While the new AEDs offer improved

Address correspondence and reprint requests to Dr. Elizabeth J. Donner, Division of Neurology, The Hospital for Sick Children, 555 University Avenue, Toronto, Ontario M5G 1X8, Canada. E-mail: elizabeth.donner@sickkids.ca. tolerability, pharmacokinetic properties, and side effect profiles, the ideal AED does not yet exist. This ideal drug would have a broad spectrum of anticonvulsant activity, such as valproic acid; be safe with no drug-drug interactions, such as gabapentin; have a long half-life allowing once daily dosing, such as phenobarbital; and have no cognitive or behavioral side effects and teratogenic effects. The ideal AED would have a use-dependent mechanism, in which the drug is dormant in the interictal state and activated by the epileptogenic process. Above all, the ideal AED would be fundamentally antiepileptogenic, altering the natural history of epilepsy. No available AED has been proven to alter the epileptogenic process; rather, these medications are only anticonvulsant, providing only symptomatic relief from seizures.

\section{DEVELOPMENT OF NEW ANTIEPILEPTIC DRUGS}

The relative flood of new AED in the last 10 years was encouraged by the development of the AED screening program by the U.S. National Institutes of Health (NIH). Historically, AEDs have been discovered by serendipity, although with new understandings about the mechanisms of epileptogenesis, we can expect to see more designer drugs targeted at specific mechanisms. At the present time, any new drug suspected of having clinical potential as an AED can be tested in a host of animal model 


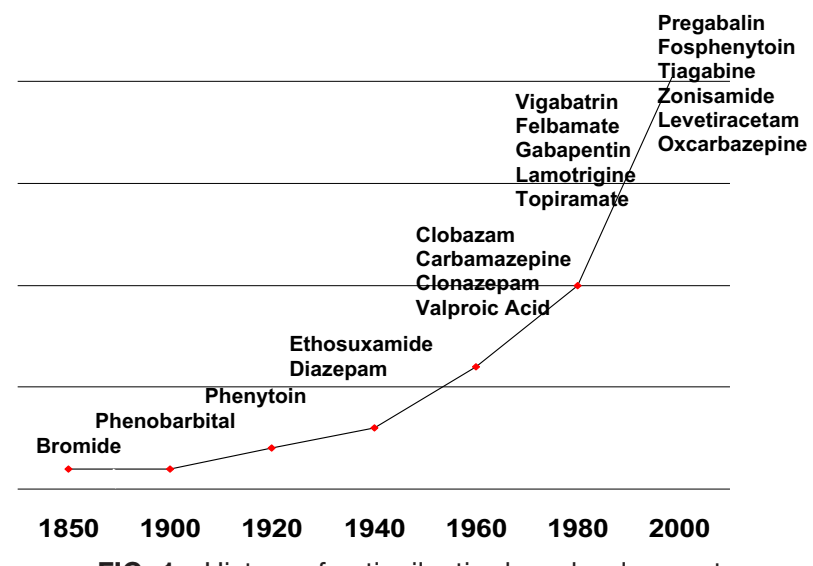

FIG. 1. History of antiepileptic drug development.

screens set up by the NIH designed to predict anticonvulsant activity against particular seizure types. ${ }^{3}$

The routine screening of compounds for anticonvulsant activity begins with an evaluation of the test agent's ability to protect adult rodents against seizures in the maximal electroshock model and the threshold pentylenetetrazol chemoconvulsant model. Screening for toxicity generally involves the rotarod test, a test of motor coordination rather than cognition or memory. These screening paradigms are used to calculate the therapeutic index, a ratio of the toxic dose to the effective dose. A high ratio indicates promise for the market and leads to more careful preclinical screening in other animal models that use adult male rodents with normal brains. If the therapeutic promise is verified, and particularly if a broad anticonvulsant spectrum is found, then the drug will progress to teratogenic testing in animals. If there is no, or limited, potential for teratogenicity, clinical pharmacokinetic and toxicological testing is undertaken in phase 1 trials. Finally, if the putative AED passes these hurdles, clinical efficacy testing begins, usually as add on treatment in adult patients with medically refractory localization-related epilepsy. These drugs are tested in children only after efficacy is shown in adults. Hence, the majority of AEDs used in childhood epilepsy were developed in adult animals for adult patients.

\section{MECHANISMS OF ACTION OF ANTIEPILEPTIC DRUGS}

The commonly employed term "antiepileptic drug" is a misnomer. These drugs are antiseizure or anticonvulsant, but do not alter the natural history of epilepsy. ${ }^{4}$ The AEDs provide purely symptomatic treatment for seizure suppression and, therefore, are not truly antiepileptic.

To exert anticonvulsant activity, a drug must act at one or more target molecules in the brain that are involved in seizuregenesis. Currently there are no drugs that target the cascade of signaling changes in the brain that represent the epileptogenic process. Rather, virtually all of the available AEDs, both old and new, are aimed at the end result of epileptogenesis, the seizure. This is generally accomplished by modifying the bursting properties of neurons and reducing synchronization in both localized and generalized neuronal circuits. To achieve these aims the drugs target one or more molecules in the brain, virtually all intended to either enhance GABA-mediated inhibition or decrease glutamate-mediated excitation, with the noted exception of absence seizures, in which the target is more thalamocortical circuitry. ${ }^{5}$ These targets include ion channels, neurotransmitter transporters, and neurotransmitter metabolic enzymes. The targets of specific AEDs are summarized in Table 2 and are discussed under each AED reviewed below.

\section{CONSIDERATIONS IN THE TREATMENT OF EPILEPSY IN CHILDREN}

Childhood is a vulnerable time developmentally, socially, and cognitively. The care of children with epilepsy provides some unique challenges to the treating physician.

Pharmacokinetics are unique in children. Drug clearance is highest in neonates, up to four times that of adults. Drug clearance then declines with age, reaching adult values in adolescence. This can result in the need for more frequent monitoring of drug levels and alterations in dose in children. ${ }^{6}$

Children present with seizure types and syndromes not seen in adults. Infantile spasms are an excellent example of an age-related seizure type that may present in association with a variety of underlying brain disorders. Childhood absence epilepsy is a well-characterized epilepsy syndrome that presents at school age and usually resolves by adulthood.

Comorbid cognitive and behavioral conditions are very common in children with epilepsy. While it is difficult to differentiate the effects of seizures, AED treatment, and underlying neuropathology on the cognitive profiles of children with epilepsy, there is no doubt that children with epilepsy are at risk for learning difficulties.

TABLE 1. New AED in the Last 10 Years

Felbamate*

Fosphenytoin

Gabapentin

Lamotrigine

Levetiracetam

Oxcarbazepine

Pregabalin

Tiagabine

Topiramate

Vigabatrin $^{\dagger}$

Zonisamide

* Felbamate is not considered first-line therapy. ${ }^{\dagger}$ Vigabatrin is not approved for use in the United States. 
TABLE 2. Antiepileptic Drugs and Their Molecular Targets

\begin{tabular}{|c|c|c|c|c|c|c|c|c|c|c|}
\hline Drug & $\begin{array}{c}\text { Sodium } \\
\text { Channels* }\end{array}$ & $\begin{array}{l}\text { Calcium } \\
\text { Channels* }\end{array}$ & $\begin{array}{c}\text { GABA } \\
\text { System* }\end{array}$ & $\begin{array}{l}\text { Glutamate } \\
\text { Receptors* }\end{array}$ & $\begin{array}{c}\text { Partial } \\
\text { Seizure }\end{array}$ & $\begin{array}{c}\text { GTC } \\
\text { Seizure }\end{array}$ & $\begin{array}{l}\text { Absence } \\
\text { Seizure }\end{array}$ & $\begin{array}{c}\text { Myoclonic } \\
\text { Seizure }^{\ddagger}\end{array}$ & $\begin{array}{l}\text { Infantile } \\
\text { spasms }^{\ddagger \S}\end{array}$ & $\begin{array}{l}\text { Lennox } \\
\text { Gastaut }\end{array}$ \\
\hline \multicolumn{11}{|c|}{ Predominant sodium (and calcium) channel activity } \\
\hline Phenytoin & $\mathrm{I}_{\mathrm{NaF}}, \mathrm{I}_{\mathrm{NaP}}$ & & & & + & + & - & - & & \\
\hline Carbamazepine & $\mathrm{I}_{\mathrm{Naf}}$ & & & & + & + & - & - & & \\
\hline Oxacarbazepine & $\mathrm{I}_{\mathrm{NaF}}$ & & & & + & + & - & - & & \\
\hline Lamotrigine & $\mathrm{I}_{\mathrm{NaF}}$ & HVA & & & + & + & + & $(+/-)$ & & + \\
\hline Zonisamide & $\mathrm{I}_{\mathrm{NaF}}$ & T-type & & & + & + & $(+)$ & $(+)$ & $(+)$ & $(+)$ \\
\hline \multicolumn{11}{|c|}{ Mixed, complex or poorly understood actions } \\
\hline Valproate & $\begin{array}{l}\mathrm{I}_{\mathrm{NaF}} ? \\
\mathrm{I}_{\mathrm{NaP}} ?\end{array}$ & T-type? & $\begin{array}{c}\uparrow \text { GABA } \\
\text { turnover }\end{array}$ & & + & + & + & + & & $(+)$ \\
\hline Felbamate & $\mathrm{I}_{\mathrm{NaF}}$ & HVA & $\mathrm{GABA}_{\mathrm{A}} \mathrm{R}$ & NMDA & + & + & $(+)$ & & & + \\
\hline Topiramate & $\mathrm{I}_{\mathrm{NaF}}, \mathrm{I}_{\mathrm{NaP}}$ & HVA & $\mathrm{GABA}_{\mathrm{A}} \mathrm{R}$ & KA/AMPA & + & + & $(+)$ & $(+)$ & $(+)$ & + \\
\hline Ethosuximide & $\mathrm{I}_{\mathrm{NaP}} ?$ & T-type & & & - & - & + & & & \\
\hline Gabapentin & & $\operatorname{HVA}(\alpha 2 \delta)$ & $\begin{array}{c}\uparrow \mathrm{GABA} \\
\text { turnover }\end{array}$ & & + & + & - & - & & \\
\hline Levetiracetam $\|$ & & HVA & $\begin{array}{c}\text { Reverses } \\
\text { DMCM }\end{array}$ & & + & $(+)$ & $(+)$ & $(+)$ & & \\
\hline \multicolumn{2}{|c|}{ GABA-mediated mechanisms } & HVA & $\mathrm{GABA}_{\mathrm{A}} \mathrm{R}$ & AMPA & + & + & - & & & \\
\hline Benzodiazepines & & & $\mathrm{GABA}_{\mathrm{A}} \mathrm{R}$ & & + & + & + & + & & $(+)$ \\
\hline Vigabatrin & & & GABAT & & + & + & - & - & + & $(+)$ \\
\hline Tiagabine & & & $\begin{array}{l}\text { GABA- } \\
\text { transporter }\end{array}$ & & + & + & - & & & \\
\hline
\end{tabular}

* Molecular targets. Not all molecular targets are shown: additional targets are discussed in the text. ${ }^{\ddagger}$ Clinical efficacy of drugs on symptoms. Clinical evidence:"+" indicates controlled trials or several open-label trials and general acceptance of utility; parentheses indicate less extensive base of evidence. "-" indicates evidence of lack of ellicacy or worsening. ${ }^{\S} \mathrm{A}$ catastrophic epilepsy syndrome usually beginning in the first year of life in which there are typically "jackknife spasms" (myoclonic seizures involving the muscles of the neck, trunk and limbs, with nodding of the head and stiffening of the arms) and a disorganized cortical discharge termed hypsarrhythmia. "Levetiractam binds with high affinity to synaptic vesicle protein $2 \mathrm{~A}$ (SV2A), a ubiquitous $90 \mathrm{kDa}$ protein that is associated with synaptic vesicles and is believed to participate in the regulation of $\mathrm{Ca}^{24}$-dependent neurotransmitter release; SV2A-knockout mice exhibit seizures ${ }^{138}$, AMPA, $\alpha$-amino-3hydroxy-5-methyl-4-isoxazole-propionic acid; GABA, $\gamma$-aminobutyric acid; GABA, ${ }^{\mathrm{A}} \mathrm{R}$. GABA, ${ }^{\mathrm{A}}$ receptor; GTC, generalized tonic-clonic; HVA, high voltage activated; $\mathrm{I}_{\mathrm{NAF}}$, fast sodium current; $\mathrm{I}_{\mathrm{NaP}}$, persistent sodium current; KA, kainate; NMDA, $N$-methyl-o-aspartate. DMCM (methyl-6,7-dimethoxy-4-ethyl- $\beta$-carboline-3-carboxylate) is a negative allosteric modulator of GABA $_{\mathrm{A}}$ receptors. Adrenocorticotropic hormone and prednisolone are recognized treatments for infantile spasms. Lamotrigine is also effective in myoclonic astatic epilepsy, but causes worsening of other forms of myoclonic epilepsy. Gabapentin has been associated with focal myoclonus. Reproduced with permission from Rogawski MA, Loscher W. The neurobiology of antiepileptic drugs. Nat Rev Neurosci 5:553-564, Copyright 2004, Nature. All rights reserved.

Furthermore, conditions such as attention deficit and hyperactivity disorder, autism, and mental retardation are more common in children with epilepsy. ${ }^{7,8}$ These conditions may complicate the initial diagnosis of epilepsy in children and often require consideration when selecting an AED. There is increasing evidence that even conditions once believed to be "benign" are associated with attention and learning disorders. ${ }^{9-11}$

Measures of health-related quality of life in children with epilepsy demonstrate increased problems with mental health, social roles, and self-esteem compared with healthy children. ${ }^{12}$ Even when compared with children with other chronic illnesses, such as asthma, children with epilepsy display more school and social problems. ${ }^{13}$ There is evidence that these issues persist into adulthood, as even when seizures are controlled, people with epilepsy attain lower educational levels, are less likely to marry, and are more often unemployed. ${ }^{14}$

\section{CONSIDERATIONS IN AED SELECTION IN CHILDREN}

There are multiple considerations in choosing an AED. The most critical factor is the type of seizure or epilepsy syndrome, particularly because certain AED are known to exacerbate specific seizure types. (Table 3) Issues of pharmacokinetics, side effect profile and drug-drug interactions also play a significant role in drug selection. Considerations in the selection of AED are listed in Table 4.

Identification of epilepsy syndromes is particularly relevant in pediatrics, as most of these conditions present in childhood and syndrome identification may help to guide diagnostic and genetic tests, direct treatment, inform prognosis and provide insight into pathophysiologic mechanisms. A classification of epilepsy syndromes has been devised and revised by the International League Against Epilepsy. ${ }^{15}$ 
TABLE 3. Exacerbation of Specific Seizure Types by $A E D$

\begin{tabular}{ll}
\hline AED & \multicolumn{1}{c}{ Seizure Type Exacerbated } \\
\hline BDZ & Tonic seizures in Lennox-Gastant syndrome \\
CBZ & Absence, atonic, myoclonic \\
OCZ & Atonic, myoclonic \\
PHT & Absence, atonic, myoclonic \\
PB & Absence, atonic \\
LTG & Myoclonic, atypical absence \\
TGB & Absence \\
\hline
\end{tabular}

$\mathrm{BDZ}=$ benzodiazepines; $\mathrm{CBZ}=$ carbamazepine; $\mathrm{OCZ}=$ oxcarbazepine; PHT $=$ phenytoin; $\mathrm{PB}=$ phenobarbital; $\mathrm{LTG}=$ lamotrigine; $\mathrm{TGB}=$ tiagabine.

\section{NEW DRUGS IN THE TREATMENT OF EPILEPSY IN CHILDREN}

The remainder of this review will outline the new AEDs available for the treatment of epilepsy in children.

\section{Felbamate (Felbatol®)}

Felbamate gained approval for use in the United States in 1993, making it the first new AED to come to market in 15 years. Initially, no serious adverse effects were recognized. Unfortunately, within the first year of approval, with about 100,000 exposures, two major, lifethreatening adverse side effects emerged, aplastic anemia and hepatic failure. While the latter complications seemed to occur in conjunction with felbamate polytherapy, the former was far more serious because it seemed to have the potential to occur with felbamate monotherapy and because it was more deadly.

Reports suggested that felbamate-related aplastic anemia was idiopathic and occurred most commonly in adult women. Few children under the age of 14 have been reported with this complication. The incidence of aplastic anemia with felbamate may be as high as 1:8000. ${ }^{16}$ Felbamate remains on the market in the United States but with a black box warning for aplastic anemia and hepatic failure and is not considered a first-line anticonvulsant medication. ${ }^{17}$ Rather, this drug is restricted to only the most intractable patients with epilepsy and can be administered only by a neurologist. Felbamate is not available in Canada or Europe.

The production of a reactive metabolite, atropaldehyde

TABLE 4. Considerations in the Selection of Antiepileptic Drugs

- Seizure type or epilepsy syndrome

- Side effect profile

- Mechanism of action

- Drug interactions

- Pharmacokinetic profile

- Ease and speed of drug initiation

- Need for laboratory monitoring

- Cost has been hypothesized as the toxic intermediate resulting in both liver failure and aplastic anemia. There is no predictive test for aplastic anemia with felbamate. Since 1994 , it is estimated that $8000-10,000$ patients are treated annually with felbamate. Two additional cases of aplastic anemia have been reported since the initial cases occurred. To date, there have been no additional reports of liver failure. ${ }^{18}$

Felbamate is related to the muscle relaxant meprobamate and has been shown to have efficacy in LennoxGastaut syndrome and partial seizures in children. ${ }^{19,20}$ Felbamate has a broad spectrum, perhaps analogous to that seen with valproic acid, with activity against generalized convulsive, partial, and absence seizures. ${ }^{21} \mathrm{~A}$ number of different mechanisms of action for felbamate have been proposed. ${ }^{17}$ These include sodium channel blockade, calcium channel blockade, and antagonisms of NMDA and AMPA receptors.

A practical disadvantage of felbamate is the short halflife, requiring three times per day dosing. Furthermore, its route of elimination is over $90 \%$ hepatic, resulting in major interactions with other AEDs. This proved to be a significant problem since felbamate was used almost exclusively as an add-on drug in intractable epilepsy, as is any new AED when it first appears on the market. Felbamate was associated with a $30 \%$ decrease in carbamazepine with a concomitant increase in carbamazepine metabolites. In addition a $20-50 \%$ increase in phenytoin levels and a $25-50 \%$ increase in valproic acid levels were observed to occur when these drugs were used with felbamate. Felbamate is supplied as 400 and $600 \mathrm{mg}$ tablets and in an oral suspension of $600 \mathrm{mg} / 5 \mathrm{~mL}$.

\section{Fosphenytoin (Cerebyx $\left.{ }^{\circledR}\right)$}

Fosphenytoin is a prodrug of phenytoin, which was developed to avoid the adverse effects associated with the parenteral administration of phenytoin, i.e., local pain after intravenous administration and more serious adverse effects such as cardiovascular complications. Fosphenytoin is rapidly and totally converted to phenytoin; $1.5 \mathrm{mg}$ of fosphenytoin yields $1 \mathrm{mg}$ of phenytoin. The anticonvulsant properties of fosphenytoin are fully attributed to phenytoin, which acts at the voltage-gated sodium channel. To avoid confusion, fosphenytoin is packaged in phenytoin equivalents (PE) and is ordered from the hospital pharmacy in that way. It may be used intravenously or intramuscularly. Fosphenytoin is most commonly used in the treatment of status epilepticus or as a substitute for oral phenytoin.

Intravenous administration results in a reduced incidence of pain and burning at the infusion site compared with phenytoin and the tachyarrhythmia that has been associated with phenytoin has not been reported with fosphenytoin. ${ }^{22}$ For these reasons, fosphenytoin has become the standard of care in many institutions. The high 
cost of fosphenytoin compared with phenytoin has prompted some discussion of the cost benefit of this drug.

\section{Gabapentin (Neurontin ${ }^{\circledR)}$}

Gabapentin was approved in 1993 and is indicated as adjunctive therapy for partial seizures with and without secondary generalization in patients 3 years and older. It is effective for some children with refractory partial seizures. ${ }^{18}$ Gabapentin is also frequently prescribed for neuropathic pain.

Gabapentin is structurally related to the inhibitory neurotransmitter GABA, however, it does not bind to GABA receptors. It is known to inhibit glutamate synthesis, potentiate GABA release, and act as a weak inhibitor of GABA transaminase. Gabapentin may also act at voltage-gated calcium channels. Despite these experimental observations, the precise anticonvulsant mechanism of action is not known. ${ }^{23}$

This drug initially was initially considered to be of low potency; however this appears related to the low doses used when the drug first became available. Clinical practice has demonstrated good efficacy against partial seizures at higher doses than originally proposed. However, higher dosing may be limited by saturable gastric absorption and three times per day dosing is usually required. A double-blinded, placebo-controlled study of gabapentin as add-on therapy in children with refractory partial seizures demonstrated superior efficacy in controlling partial seizures and secondarily generalized seizures compared with placebo with good tolerability, and these results have been replicated. ${ }^{24}$ Gabapentin has also been proven effective as monotherapy in the control of seizures associated with benign childhood epilepsy with centrotemporal spikes. ${ }^{25,26}$

One of the major advantages of gabapentin is that is $100 \%$ excreted unchanged via the kidneys and therefore has virtually no drug-drug interactions. It is easy to use as an add-on drug, or in children on chemotherapy or other medications for which drug interactions would not be tolerated, as well as in children with liver function impairment. The side effects are mild, usually related to somnolence. Weight gain has also been reported. No serious life-threatening adverse effects have been identified. ${ }^{17,23,24,27}$

The dose of gabapentin is $20-50 \mathrm{mg} / \mathrm{kg} / \mathrm{day}$, with doses of up to $90 \mathrm{mg} / \mathrm{kg} /$ day reported. With a short half-life of 5-7 h, this drug must be given in three divided doses. Gabapentin is supplied as 100,300 , or 400 mg capsules; 600 or $800 \mathrm{mg}$ tablets; or in an oral suspension containing $250 \mathrm{mg} / \mathrm{mL}$.

\section{Lamotrigine (Lamictal $\left.{ }^{\circledR}\right)$}

Lamotrigine was approved in 1994 for use as an adjunctive treatment in adults with partial-onset seizures. It has now been approved for adjunctive therapy for partial seizures in children aged 2 years or older, as well as monotherapy in adults with epilepsy when converting from valproic acid therapy and in children with generalized seizures associated with Lennox-Gastaut syndrome. ${ }^{17,26}$

Lamotrigine exerts it anticonvulsant effects through voltage- and use-dependent blockade of voltage-dependent sodium channels and inhibition of high-voltage activation $\mathrm{Ca}^{2+}$ currents possibly through inhibition of presynaptic $\mathrm{N}$-type $\mathrm{Ca}^{2+}$ channels. ${ }^{28}$

Lamotrigine has been shown to be effective as add-on therapy of refractory partial and generalized seizure in children. ${ }^{29,30}$ This drug is considered to have a broad spectrum of action, analogous to valproic acid, effective in partial seizures as well as a variety of generalized epilepsies, including absence seizures and myoclonic seizures. It has been proven effective in Lennox-Gastaut syndrome and is commonly used in childhood absence epilepsy as well. ${ }^{31}$

Lamotrigine is known to produce a skin rash in up to $5-10 \%$ of patients. These rashes have the potential to be severe and life threatening and Stevens-Johnson syndrome may occur rarely. Severe rash occurs more often in children; up to $1 \%$ incidence has been reported. ${ }^{32}$ The risk of rash is related to the dose and the speed of titration, which necessitates low starting doses and slow titration. Other risk factors for development of serious rash are younger age and concomitant use of valproic acid, discussed below. Additional side effects include dizziness, headache, ataxia, and diplopia. Lamotrigine may worsen myoclonic and atypical absence seizures, although it may also help them.

Lamotrigine is metabolized by the liver and thereby sensitive to interactions with other drugs that induce hepatic enzymes. Lamotrigine generally does not cause pharmacokinetic interactions, however, it has been associated with a $25 \%$ decrease in levels of valproic acid. Hepatic enzyme inducers such as carbamazepine and phenytoin will decrease the half life of lamotrigine to $15 \mathrm{~h}$, which may require dosing alterations. The most important interaction to note is that the half-life is very prolonged, $60 \mathrm{~h}$, when lamotrigine is used in combination with valproic acid. ${ }^{33}$ The elevated lamotrigine levels that occur when used in conjunction with valproic acid significantly increase the risk of skin rash and care must be taken when using these drugs in combination. To reduce the risk of severe skin rash, a long, slow titration of dose is required when used alone or in combination with other AEDs. ${ }^{17}$ Oral contraceptives are associated with a $50 \%$ reduction of the mean steady-state plasma concentration of lamotrigine. ${ }^{27}$

The dose of lamotrigine is $1-10 \mathrm{mg} / \mathrm{kg} / \mathrm{day}$ in children and $3-15 \mathrm{mg} / \mathrm{kg} /$ day in infants. Lamotrigine has a long half-life, which permits once or twice per day dosing. The half-life when used in monotherapy is $24 \mathrm{~h}$ and 
decreases to $15 \mathrm{~h}$ when used in polytherapy with drugs that induce hepatic enzymes. Lamotrigine is supplied as $25,100,150$, and $200 \mathrm{mg}$ tablets and 2,5 , and $25 \mathrm{mg}$ chewable tablets.

\section{Oxcarbazepine (Trileptal®)}

Oxcarbazepine was approved by the FDA in 2000 and is indicated for use as monotherapy or adjunctive therapy for partial-onset seizures in patients aged 4 years or older. It is an analog of carbamazepine that was designed to have similar efficacy and fewer adverse effects due to the lack of formation of carbamazepine's toxic metabolite, carbamazepine-10,11-epoxide. ${ }^{34}$ Oxcarbazepine and its active metabolite, 10-monohydroxy derivitive, limit high-frequency neuronal firing by blocking voltage-dependent sodium channels. The metabolite produces a reversible dose-dependent decrease in high-voltage activated calcium currents and reduces glutamatergic neurotransmission as well. ${ }^{18}$

Oxcarbazepine has been evaluated as adjunctive and monotherapy for partial seizures. Studies in adults show similar efficacy to phenytoin, carbamazepine, and valproic acid in patients with newly diagnosed partial-onset epilepsy, with fewer adverse effects. ${ }^{35}$ A randomized controlled study in children showed equal efficacy to phenytoin, but better tolerability. ${ }^{36}$ There is little evidence to suggest that seizures that are not responsive to adequate therapy with carbamazepine will respond to oxcarbazepine, although switching to oxcarbazepine may improve tolerability and carry a higher financial cost.

Oxcarbazepine is rapidly metabolized to its active metabolite, the 10-monohydroxy derivative. Metabolism is hepatic, however, there is no altered pharmacokinetics in the presence of hepatic or renal dysfunction. The autoinduction seen with carbamazepine does not occur with oxcarbazepine. Similarly, oxcarbazepine has significantly fewer drug interactions than carbamazepine. Oxcarbazepine does not induce the cytochrome P450 system as seen with carbamazepine. It does affect the CYP3A subfamily and, consequently, may lower oral contraceptive levels. ${ }^{37}$

A further advantage of oxcarbazepine is fewer and less severe side effects than carbamazepine. Skin rash is less frequent; however, serious reactions such as StevensJohnson syndrome and toxic epidermal necrolysis have been reported. Up to $30 \%$ of patients who experience a rash from carbamazepine will develop a similar reaction to oxcarbazepine, which necessitates that care be taken in patients with a history of severe skin reaction to carbamazepine. There have been no significant changes in white blood cell counts or liver enzyme levels in clinical trials of oxcarbazepine. ${ }^{27}$ The more common adverse effects of oxcarbazepine are dose related and consist of dizziness, diplopia, nausea, somnolence, and ataxia. A potentially serious adverse effect is hyponatremia, which may be clinically significant in up to $2.5 \%$ patients, although is reported to be more rare in children. Serum sodium levels should be monitored when clinically indicated. ${ }^{38}$

Oxcarbazepine is dosed at $10-50 \mathrm{mg} / \mathrm{kg} /$ day divided in twice per day dosing. Patients may be directly switched from carbamazepine to oxcarbazepine using a ration of 1.5:1 oxcarbazepine:carbamazepine for doses up to $1500 \mathrm{mg} /$ day of carbamazepine and 1:1 for higher daily doses. ${ }^{39}$ Oxcarbazepine is supplied as 150, 300, and $600 \mathrm{mg}$ tablets and in an oral suspension containing $300 \mathrm{mg} / 5 \mathrm{~mL}$.

\section{Pregabalin $\left(\right.$ Lyrica $\left.{ }^{\circledR}\right)$}

Pregabalin is the newest AED to come to market in the United States, approved in 2005 for adjuvant therapy of partial seizures in adults. It was previously approved for the treatment of neuropathic pain associated with diabetic peripheral neuropathy. This drug is a structural analog to GABA, but functionally unrelated. It is thought to exhibit its anticonvulsant activity by binding to the $\alpha-2-\delta$ subunit of the voltage-gated calcium channel. ${ }^{40}$

Pregabalin is stated to have very rapid absorption, with steady-state serum levels achieved within $48 \mathrm{~h}$, which may prove to be a favorable pharmacokinetic property. It is excreted virtually unchanged by the kidneys and does not induce or inhibit liver enzymes. ${ }^{40}$

Pregabalin has been demonstrated to be more effective than placebo as add-on therapy in patients 12 years of age and older with refractory partial seizures with or without secondary generalization. ${ }^{41}$ Dosing in clinical trials ranged from 150 to $600 \mathrm{mg}$ per day in adults. Dosing recommendations are not available for children and there is no significant experience with this drug in children to date. Pregabalin is supplied in $25,50,75,100$, 200, 225, and $300 \mathrm{mg}$ tablets.

\section{Levetiracetam (Keppra $\left.{ }^{\circledR}\right)$}

Levetiracetam was approved in 1999 for the adjunctive treatment of adults with partial-onset seizures. Levetiracetam is a pyrolidone, similar to piracetam. The mechanism of action of levetiracetam is unknown but of considerable interest since there are some experimental animal data to suggest that this drug might actually have antiepileptogenic as well as anticonvulsant properties. ${ }^{42}$ Recently, it has been proposed that levetiracetam might affect fundamental mechanisms of neurotransmission by binding to a novel protein binding site, an integral membrane protein present on synaptic vesicles. ${ }^{43}$

While clinical trials have focused on adjuvant therapy in partial seizures, there is experimental evidence from animal models that levetiracetam is also effective against absence seizures. ${ }^{27}$ Anecdotal evidence suggests efficacy in atypical absence seizures. Open label trials in children have demonstrated good efficacy and tolerability in refractory mixed seizure disorders. ${ }^{44,45}$ A prospective, open label study has provided preliminary evidence for 
the anticonvulsant efficacy of levetiracetam in the pediatric population against a number of different seizure types with $46 \%$ of the patients showing a seizure frequency reduction of more than $50 \%$ to treatment. The maximal dose in that study was $60 \mathrm{mg} / \mathrm{kg}^{46}$

Levetiracetam is excreted primarily by the kidneys, with minimal hepatic metabolism. It is not affected by hepatic enzyme-inducing AEDs and does not affect the metabolism of other AEDs. Levetiracetam is generally considered to be quite safe, with no severe adverse effects noted. Somnolence, asthenia, and common infection were the most frequent side effects noted in clinical trials and were not dose related. The most significant adverse effects are behavioral, such as anxiety and agitation. Psychotic symptoms have also been reported in children. ${ }^{47}$ These behavioral effects appear to be reversible with discontinuation or dose adjustment of the drug.

The pediatric dose is $10 \mathrm{mg} / \mathrm{kg} / \mathrm{day}$ to start with a gradual increase to a maintenance dose of $60 \mathrm{mg} / \mathrm{kg} / \mathrm{day}$. Levetiracetam is supplied as 250,500 , and $750 \mathrm{mg}$ tablets.

\section{Tiagabine (Gabitril®)}

Tiagabine was approved in 1997 for adjunctive treatment of partial seizures in patients 12 years of age and older. Tiagabine offers a novel mechanism of action, selective inhibition of GABA reuptake into neurons and glia, which enhances GABA-mediated inhibition. Modest efficacy has been demonstrated in several randomized controlled trials of adjuvant treatment in partial seizures in adults compared to placebo and carbamazepine or phenytoin. Monotherapy trials have shown promising results in adults. Pediatric studies have been small but suggested modest efficacy; further pediatric trials are needed. ${ }^{17,48}$

Tiagabine has been implicated in episodes of atypical absence status epilepticus. ${ }^{27,49,50}$ Although the validity of this phenomenon has been challenged, the exacerbation of experimental absence seizures by GABAergic agonists, including direct $\mathrm{GABA}_{\mathrm{A}}$ or $\mathrm{GABA}_{\mathrm{B}}$ receptor agonists and indirect GABA agonists, such as GABA transaminase inhibitors (e.g., vigabatrin) and GABA uptake inhibitors, such as tiagabine, is well established. ${ }^{51,52}$ Concentric field defects similar to those associated with vigabatrin treatment, another drug that increases synaptic concentrations of GABA, have not been shown to occur with tiagabine..$^{53,54}$

Tiagabine undergoes hepatic metabolism via the cytochrome P450 system. The half-life is 5-8 $\mathrm{h}$, which is reduced to $2-3 \mathrm{~h}$ in patients also taking hepatic enzymeinducing AEDs, therefore, the potential for drug interactions exist. Conversely, tiagabine does not inhibit or induce hepatic enzymes and therefore does not affect the concentration of other drugs. The elimination of tiagabine is nearly doubled in children. ${ }^{55}$
The most common side effects of tiagabine are doserelated somnolence, confusion, ataxia, and dizziness, which may be reduced with more frequent dosing schedules. ${ }^{17}$

In children 12 years of age and older, on an enzymeinducing AED, the starting dose of tiagabine is $4 \mathrm{mg} /$ day, to increase by $4 \mathrm{mg} /$ week to a maximum of dose of 56 $\mathrm{mg} /$ day. Significantly lower doses are recommended in patients not taking an inducing AED. Tiagabine is supplied as 2, 4, 12, and $16 \mathrm{mg}$ tablets.

\section{Topiramate (Topamax $®)$}

Topiramate has been available in the United States since 1997, when it was approved for use as adjunctive therapy for patients older than 2 years of age with primary generalized tonic-clonic seizures, partial-onset seizures, or seizures associated with Lennox-Gastaut syndrome. Topiramate is also used for migraine prophylaxis.

Electrophysiological and biochemical evidence suggests that topiramate, at pharmacologically relevant concentrations, blocks voltage-dependent sodium channels, augments the activity of the neurotransmitter gammaaminobutyrate at some subtypes of the GABA-A receptor, antagonizes the AMPA/kainate subtype of the glutamate receptor, and inhibits the carbonic anhydrase enzyme, particularly isozymes II and IV. ${ }^{56-61}$ Topiramate appears to have no effect on NMDA receptor function. ${ }^{62}$

Topiramate has demonstrated efficacy in placebo-controlled trials in partial-onset seizures in children, Lennox-Gastaut syndrome, and infantile spasms. ${ }^{63-66} \mathrm{~A}$ recent open prospective trial demonstrated efficacy and tolerability in children younger than 2 years of age. ${ }^{67}$

Topiramate has not been associated with any lifethreatening adverse events; however, there is a risk of serious hyperchloremic, nonanion gap metabolic acidosis (lowering of serum bicarbonate levels) for which measurement of baseline and periodic serum bicarbonate levels is recommended. Renal stones may occur. Oligohidrosis and hyperthermia occurs most often in hot weather and has been reported in children. In adults, acute myopia and secondary angle closure glaucoma may occur.

The most significant adverse effects in clinical use relate to cognitive dysfunction. In children, this may present as deterioration in school performance, reduced use of language, or reports of poor attention. Somnolence may contribute to this problem and may be reduced by starting at a low dose $(1 \mathrm{mg} / \mathrm{kg} /$ day $)$ and increasing slowly. Anorexia can also be a significant adverse effect of topiramate and may require discontinuation of the drug in small children with weight loss.

This drug has a long half-life of $10-23 \mathrm{~h}$ and is given in one or two daily doses. Topiramate is excreted unchanged via the kidneys. The plasma concentration of 
topiramate is reduced by $50 \%$ by hepatic enzyme inducers such as phenytoin and carbamazepine. However, topiramate has little effect on steady-state concentrations of phenytoin, carbamazepine, and valproate. Topiramate may reduce the effectiveness of oral contraceptives.

The dose of topiramate in children is $6-8 \mathrm{mg} / \mathrm{kg} / \mathrm{day}$ and the usual adult dose is $200-600 \mathrm{mg} /$ day. Doses of up to $30 \mathrm{mg} / \mathrm{kg} / \mathrm{day}$ have been reported. Younger patients require higher doses of topiramate to achieve serum topiramate concentrations comparable to adults. ${ }^{68}$ Topiramate is supplied as $25,50,100$, and $200 \mathrm{mg}$ tablets and 15 and $25 \mathrm{mg}$ sprinkle capsules that may be swallowed whole or opened and sprinkled onto soft food.

\section{Vigabatrin (Sabril®)}

Vigabatrin was initially licensed in 1989; however it has never been approved for use in the United States. Recently it has fallen into disfavor in Europe and Canada as well, because of the association with visual toxicity in the form of irreversible constriction of the visual fields. ${ }^{69}$ The reason to consider this drug here is because it has been shown to be effective against infantile spasms in children and is used widely in this regard. A recent practice parameter on the treatment of infantile spasms was only able to conclude that vigabatrin is possibly effective in infantile spasms, because most of the evidence for the therapeutic efficacy of vigabatrin in this regard comes from uncontrolled clinical trials. ${ }^{70}$ However, because of the potential risk of more severe adverse effects with adrenocorticotropin hormone, the other common treatment for infantile spasms, some clinicians prefer to use vigabatrin as first-line treatment, particularly in countries other than the United States, where the drug is more readily available. There are further studies in children with tuberous sclerosis, suggesting that vigabatrin may be particularly effective for infantile spasms in this population. $^{71}$

Vigabatrin is an irreversible inhibitor of the enzyme responsible for the catabolism of the major inhibitory neurotransmitter in brain, GABA. It is therefore thought to act by raising the level of the inhibitory neurotransmitter, GABA, in the brain, increasing the threshold to seizures.

The most significant adverse effect of vigabatrin is retinal toxicity, manifesting as concentric visual field defects, which has been reported in up to $40 \%$ of adult patients on vigabatrin treatment. This finding has also been reported in children. Because of the high reported incidence of retinal toxicity, routine ophthalmologic screening is recommended in all children treated with vigabatrin. There is evidence that electroretinography may detect further abnormalities in children with infantile spasms treated with vigabatrin. ${ }^{72}$ In fact, there is some evidence that children with infantile spasms on vigabatrin may have compromised visual function that predates vigabatrin therapy and may be more due to the infantile spasms than the drug. ${ }^{69}$ More minor side effects include somnolence, which may be dose related. Vigabatrin is eliminated by the kidneys and is not an enzyme inducer. The only notable drug-drug interaction of vigabatrin is that it may be associated with a decrease in phenytoin levels.

The dose of vigabatrin in infantile spasms is $100-150$ $\mathrm{mg} / \mathrm{kg} / \mathrm{day}$. The half life is $5-11 \mathrm{~h}$ and it may be given once or twice daily. Vigabatrin is supplied as $500 \mathrm{mg}$ tablets or $500 \mathrm{mg}$ sachets that may be dissolved or sprinkled on food.

\section{Zonisamide (Zonegran ${ }^{\circledR}$ )}

Zonisamide has been in widespread use in Japan since 1989 and gained approval in the United States in 2000 for use in partial-onset seizures. Despite this indication, there is evidence that Zonisamide has a broad spectrum of anticonvulsant properties and is said to be very effective in generalized seizures, especially myoclonus. The mechanisms by which zonisamide is anticonvulsant are unknown. This drug has been shown to have multiple pharmacological actions that may contribute to its anticonvulsant effect. It blocks voltage-sensitive sodium and voltage-dependent calcium T-type channels, enhances GABA release, blocks the potassium-evoked glutamate response, and reduces glutamate-mediated synaptic excitation. $^{73}$

Controlled trials have demonstrated the efficacy of this drug against partial seizures in adults. ${ }^{74}$ A number of open label studies suggest that the drug has a broad spectrum of efficacy, including primarily generalized seizures, absence seizure, myoclonic seizures, and possibly infantile spasms. Favorable responses have been noted in progressive myoclonic epilepsy. ${ }^{75}$

Zonisamide undergoes hepatic metabolism via the cytochrome P450 system. The half-life is long, 50-70 h, and is reduced to $30 \mathrm{~h}$ with concomitant use of enzymeinducing AEDs. Zonisamide does not alter the metabolism of other AEDs. ${ }^{27}$ The side effects are dose related and consist of dizziness, ataxia, and anorexia. Zonisamide was reported to cause renal stones in an early study, however, this was not replicated in later trials. Hyperthermia and anhidrosis has been reported in children. Severe skin rash, Stevens-Johnson syndrome, and toxic epidermal necrolysis were seen in postmarketing experience in Japan, however, these serious skin reactions have not been seen in the United States and Europe. ${ }^{27}$ Zonisamide is a sulfonamide derivative and its use is contraindicated in patients with sulfonamide allergy. ${ }^{17}$

Zonisamide is available in 25,50 , and $100 \mathrm{mg}$ capsules. The recommended starting dose in children is $2-4$ $\mathrm{mg} / \mathrm{kg} /$ day dosed once or divided twice daily, increased every 2 weeks to a maximum dose of $12 \mathrm{mg} / \mathrm{kg} /$ day. 
TABLE 5. Summary of the US and UK Guideline Recommendations for Use of New Antiepileptic Drugs

\begin{tabular}{|c|c|c|c|c|c|c|c|c|c|c|c|c|}
\hline \multirow[b]{3}{*}{ Drug } & \multicolumn{4}{|c|}{ Newly Diagnosed Epilepsy } & \multicolumn{4}{|c|}{ Refractory Epilepsy } & & & & \\
\hline & \multicolumn{2}{|c|}{$\begin{array}{l}\text { Partial, } \\
\text { Mixed }\end{array}$} & \multicolumn{2}{|c|}{ Absence } & \multicolumn{2}{|c|}{ Partial } & \multicolumn{2}{|c|}{$\begin{array}{c}\text { Partial } \\
\text { Monotherapy }\end{array}$} & \multicolumn{2}{|c|}{$\begin{array}{l}\text { Idiopathic } \\
\text { Generalised }\end{array}$} & \multicolumn{2}{|c|}{$\begin{array}{l}\text { Symptomatic } \\
\text { Generalized }\end{array}$} \\
\hline & US & UK & US & UK & US & UK & US & UK & US & UK & US & UK \\
\hline Felbamate* & No & NA & No & NA & $\mathrm{Yes}^{\dagger}$ & NA & Yes & NA & No & NA & Yes & NA \\
\hline Gebapentin & Yes $^{\S}$ & No & No & No & Yes & Yes $^{\text {II }}$ & No & No & No & No & No & No \\
\hline Lemotrigine & Yes $^{\S}$ & Yes $\|$ & Yes $^{\S}$ & Yes" & Yes & Yes** & Yes & Yes & No & Yes** & Yes & Yes** \\
\hline Levetiracetam & No & No & No & No & Yes & Yes $^{\dagger \dagger}$ & No & No & No & No & No & No \\
\hline Oxcarbazepine & Yes & Yes $^{\text {II }}$ & No & No & Yes & Yes $^{\text {gI }}$ & Yes & Yes $^{\text {TI }}$ & No & No & No & No \\
\hline Tiagabine & No & No & No & No & Yes & Yes $\|$ & No & No & No & No & No & No \\
\hline Topiremate & $\mathrm{Yes}^{\S}$ & Yes $^{\text {II }}$ & No & No & Yes & Yes** & $\mathrm{Yes}^{\S}$ & Yes $^{\text {TI }}$ & Yes & $\mathrm{Yes}^{\dagger \neq * *}$ & Yes & Yes** \\
\hline Vigabatrin $\$$ & NA & No & NA & No & NA & Yes & NA & No & NA & No & NA & Yes $^{\text {IIIII }}$ \\
\hline Zonisamide & No & NA & No & NA & Yes ${ }^{|l| \mid}$ & NA & No & NA & No & NA & No & NA \\
\hline
\end{tabular}

None of the new drugs is recommended as first choice in newly diagnosed epilepsy by the UK guidelines (see text). NA $=$ not available. * Patients unresponsive to standard drugs in whom the risk/benefit ratio supports use. ${ }^{\dagger}$ only patients $>18$ years. ${ }^{\ddagger}$ only patients $>4$ years with Lennox-Gastaut syndrome. ${ }^{\S}$ indication not approved by FDA. ${ }^{\mathbb{I I}}$ only patients $>6$ years. ${ }^{\|}$only patients $>12$ years. $* *$ only patients $>2$ years. ${ }^{\dagger \dagger}$ only patients $>16$ years. ${ }^{\sharp \neq}$ only generalised tonic-clonic seizures. ${ }^{\S}{ }_{\text {in }}$ the UK the indications are limited to adjunctive use after failure of all other appropriate drug combinations. ${ }^{\text {TII }}$ only West syndrome. ${ }^{|i| l}$ only adults. Reproduced with permission from Beghi E. Efficacy and tolerability of the new antiepileptic drugs: comparison of two recent guidelines. Lancet Neurol 3:618-621. Copyright 2004, Elsevier. All rights reserved. ${ }^{77}$

\section{CONCLUSION}

In conclusion, it is imperative to state that there is no evidence that any of the new AEDs are more efficacious than the traditional AEDs. Rather, these new drugs offer equal efficacy with improved pharmacokinetic profiles and fewer drug-drug interactions. The new AEDs do come with a larger price tag; however, this higher cost may be offset by improved clinical outcome.

In 2004, the American Academy of Neurology (AAN), in conjunction with the American Epilepsy Society (AES) and the United Kingdom-based National Institute for Clinical Excellence (NICE), independently produced guidelines for the use of the new AEDs. Both the AAN and NICE guidelines acknowledge that the new AEDs appear to have similar efficacy to the older AEDs, but better tolerability and that there is insufficient evidence to compare the efficacy among the newer AEDs. The guidelines diverge in their recommendations for the use of new AED in the treatment of new-onset epilepsy. The AAN guidelines recommend that the new drugs, lamotrigine, gabapentin, topiramate, and oxcarbazepine be considered along with the older drugs for first-line treatment in new-onset partial epilepsy. The NICE guidelines recommend that new AEDs be considered first-line in specific clinical settings, including in woman of childbearing age and when there are concerns about drug interactions. The recommendations are summarized in Table 5 and are well reviewed by Beghi. ${ }^{76}$

It is critical to note that evidence-based recommendations are dependent on the available evidence in the literature. Thus, the absence of a recommendation for a certain AED does not imply that it is not effective in that clinical situation but may reflect an absence of available evidence because of ongoing clinical trials or other factors. The clinician may select an AED based on side effect profile, pharmacokinetic properties, and risk of

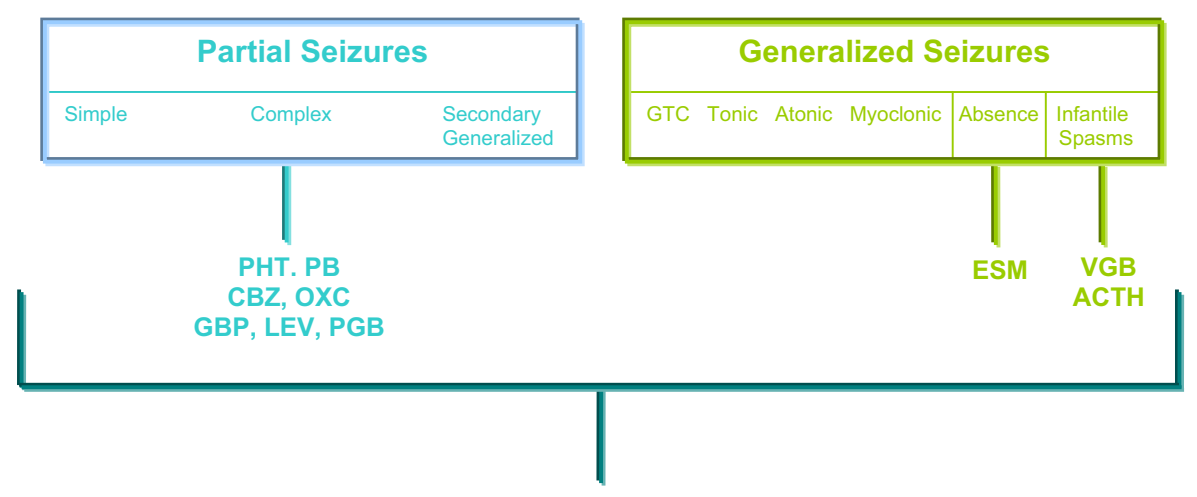

VPA, LTG, TPM, ZNS, (FBM)

FIG. 2. AED choice by seizure type. 
teratogenecity in contradiction to these guidelines (Table 4 ). Anticonvulsant choice by seizure type is presented in Figure 2.

\section{ON THE HORIZON}

There are some AEDs currently in use outside of North America, but not yet available in the United States or Canada that may be efficacious in childhood epilepsy. These include sulthiame (Ospolot $\left.{ }^{\circledR}\right)$, which has been shown to be useful in benign epilepsy of childhood with centro-temporal spikes (BECTS), and stiripentol, which is said to be particularly efficacious in severe myoclonic epilepsy of infancy. ${ }^{27}$ There are also several new AEDs currently in preclinical development, some of which have novel mechanisms of action, including actions at the $\alpha 2$-noradrenergic receptor in the brain and stabilization of neuronal membrane excitability via action on potassium currents. ${ }^{18}$ However, no drug to date appears to offer antiepileptogenic properties. Real relief for children with epilepsy and their families will have to await the development of truly antiepileptogenic drugs.

Acknowledgments: This work was supported in part by the Bloorview Children's Hospital Foundation.

\section{REFERENCES}

1. Chang BS, Lowenstein DH. Epilepsy. N Engl J Med 349:12571266, 2003.

2. Kwan P, Brodie MJ. Early identification of refractory epilepsy. $N$ Engl J Med 342:314-319, 2000.

3. White HS. Animal models of epileptogenesis. Neurology 12 [Suppl 5]:S7-S14, 2002.

4. Shinnar S, Berg AT. Does antiepileptic drug therapy prevent the development of "chronic epilepsy"? Epilepsia 37:701-708, 1996.

5. Dodson WE. Pharmacokinetic principles of antiepileptic therapy in children. In: Pediatric epilepsy diagnosis and therapy (Pellock JM, Dodson WE, Bourgeois, BFD, eds), Vol 23, Ed 2, pp 317-327. New York: Demos Medical Publishing, 2001.

6. Dunn DW. Neuropsychiatric aspects of epilepsy in children. EpilepsyBehav 4:101-106, 2003.

7. Shinnar S, Pellock JM. Update on the epidemiology and prognosis of pediatric epilepsy. J Child Neurol 17 [Suppl 1]:S4-S17, 2002.

8. Saint-Martin AD, Seegmuller C, Carcangiu R, Kleitz C, Hirsch E, Marescaux C, Metz-Lutz MN. Cognitive consequences of rolandic epilepsy. Epileptic Disord 2:S159-S165, 2001.

9. Camfield P, Camfield C. Epileptic syndromes in childhood: clinical features, outcomes, and treatment. Epilepsia 43 [Suppl 3]:2732, 2002.

10. Yung AW, Park YD, Cohen MJ, Garrison TN. Cognitive and behavioral problems in children with centrotemporal spikes. Pediatr Neurol 23:391-395, 2000.

11. Helmstaedter C, Kurthen M, Lux S, Reuber M, Elger CE. Chronic epilepsy and cognition: a longitudinal study in temporal lobe epilepsy. Ann Neurol 54:425-432, 2003.

12. Miller V, Palermo TM, Grewe SC. Quality of life in pediatric epilepsy: demographic and disease-related predictors and comparison with healthy controls. Epilepsy Behav 4:36-42, 2003.

13. Austin JK, Huster GA, Dunn D, Risinger MW. Adolescents with active or inactive epilepsy or asthma: a comparison of quality of life. Epilepsia 37:1228-1238, 1996.

14. Sillanpaa M, Jalava M, Kaleva O, et al. Long-term prognosis of seizures with onset in childhood. N Engl J Med 338:1715-1722, 1998.
15. Engel J. A proposed diagnostic scheme for people with epileptic seizures and with epilepsy: report of the ILAE task force on classification and terminology. Epilepsia 42:796-803, 2001.

16. Pellock JM. Felbamate. Epilepsia 40 [Suppl 5]:S57-S62, 1999.

17. LaRoche SM, Helmers SL. The new antiepileptic drugs: scientific review. J Am Med Assoc 291:605-614, 2004.

18. Bialer M, Johannessen SI, Kupferberg HJ, Levy RH, Perucca E, Tomson T. Progress report on new antiepileptic drugs: a summary of the Seventh Eilat Conference (EILAT VII). Epilepsy Res 61:148, 2004.

19. The Felbamate Study Group in Lennox-Gastaut Syndrome. Efficacy of felbamate in childhood epileptic encephalopathy (LennoxGastaut syndrome). N Engl J Med 328:29-33, 1993.

20. Carmant L, Holmes GL, Sawyer S, et al. Efficacy of felbamate in therapy for partial epilepsy in children. J Pediatr 125:481-486, 1994.

21. Leppik IE. Felbamate. Epilepsia 36 [Suppl 2]:S66-S72, 1995.

22. Glauser TA, Graves NM. Phenytoin and fosphenytoin. In: The treatment of epilepsy: principles and practice (Wyllie E, ed), Vol 58, Ed 3, pp 853-868. Philadelphia: Lippincott Williams \& Wilkins, 2001.

23. McLean MJ. Gabapentin. In: The treatment of epilepsy: principles and practice (Wyllie E, ed), Vol 62, Ed 3, pp 853-868. Philadelphia: Lippincott Williams \& Wilkins, 2001.

24. Appleton R, Fichtner K, LaMoreaux L, et al. Gabapentin as add-on therapy in children with refractory partial seizures: a 12-week, multicenter, double-blind, placebo controlled study. Epilepsia 40: 1147-1154, 1999.

25. Shapiro DY, Nordli D, Glauser TA, Knapp LE, Greiner M, Purcell T, Brigell M, Fichtner K, Kugler AR, Malicsi M, Smith TM, Garofalo EA. Gabapentin as add-on therapy for refractory partial seizures in children 1-36 months of age: a novel short-term, placebo-controlled trial. Epilepsia 41 [Suppl 7]:106, 2000.

26. Bialer M, Johannessen SI, Kupferberg HJ, Levy RH, Loiseau P, Perucca E. Progess report on new antiepileptic drugs: a summary of the Sixth Eilat Conference (EILAT VI). Epilepsy Res 51:31-71, 2002.

27. Bergin AM, Connolly M. New antiepileptic drug therapies. Neurol Clin N Am 20:1163-1182, 2002.

28. Gilliam FG, Gidal, BE. Lamotrigine. In: The treatment of epilepsy: principles and practice (Wyllie E, ed), Vol 63, Ed 3, pp 853-868. Philadelphia: Lippincott Williams \& Wilkins, 2001.

29. Duchowny M, Pellock JM, Graf WD, et al. A placebo-controlled trial of lamotrigine add-on therapy for partial seizures in children. Neurology 53:1724-1731, 1999.

30. Eriksson A-S, Nergardh A, Hoppu K. The efficacy of lamotrigine in children and adolescents with refractory generalized epilepsy: a randomized, double-blind, crossover study. Epilepsia 39:495-501, 1998.

31. Motte J, Trevathan E, Arvidsson JFV, et al., The Lamictal Lennox-Gastaut Study Group. Lamotrigine for generalized seizures associated with the Lennox-Gastaut syndrome. $N$ Engl $J$ Med 337:1807-1812, 1997.

32. Guberman AH, Besag FM, Brodie MJ, et al. Lamotrigine-associated rash: risk/benefit considerations in adults and children. Epilepsia 40:985-991, 1999.

33. Yuen AWC, Land G, Weatherley BC, et al. Sodium valproate acutely inhibits lamotrigine metabolism. Br J Clin Pharmacol 33:511-513, 1992.

34. Wong IC, Lahtoo SD. Adverse reactions to new anticonvulsant drugs. Drug Saf 23:35-56, 2000.

35. Beydoun A, Sachdeo RC, Kutluay E, et al. Sustained efficacy and long term safety of oxcarbazepine: one-year open-label extension of a study in refractory partial seizures. Epilepsia 44:1160-1165, 2003.

36. Guerreiro MM, Vigonius U, Pohlmann H, et al. A double-blind controlled clinical trial of oxcarbazepine versus phenytoin in children and adolescents with epilepsy. Epilepsy Res 27:205-213, 1997.

37. Sillanpaa ML. Carbamazepine and Oxcarbazepine. In: The treatment of epilepsy: principles and practice (Wyllie E, ed), Vol 56, Ed 3, pp 853-868. Philadelphia: Lippincott Williams \& Wilkins, 2001. 
38. Van Amelsvoort T, Bakshi R, Devaux CB, et al. Hyponatremia associated with carbamazepine and oxcarbazepine therapy: a review. Epilepsia 35:181-188, 1994.

39. Smith PEM. Clinical recommendations for oxcarbazepine. Seizure 10:87-91, 2001.

40. Ben-Menachem E. Pregabalin pharmacology and its relevance to clinical practice. Epilepsia 45 [Suppl 6]:13-18, 2004.

41. Brodie MJ. Pregabalin as adjunctive therapy for partial seizures. Epilepsia 45 [Suppl 6]:19-27, 2004.

42. Stratton SC, Large CH, Cox B, Davies G, Hagan RM. Effects of lamotrigine and levetiracetam on seizure-development in a rat amygdala kindling model Epilepsy Res 53:95-106, 2003.

43. Lynch B, Lambeng N, Nocka K, Kensel-Hammes P, Bajjellieh SM, Matagne A, Fuks B. The synaptic vesicle protein SV2A is the binding site for the antiepileptic drug levetiracetam. Proc Natl Acad Sci USA 10:9861-9866, 2004.

44. Bourgeois BFD, Holder DL, Valencia I, et al. Open label assessment of levetiracetam efficacy and adverse effects in a pediatric population. Epilepsia 42 [Suppl 7]:253-254, 2001.

45. Glauser T, Bebin M, Ritter F, et al. Open-label efficacy and safety of levetiracetam in pediatric patients with partial-onset seizures (abstract). Epilepsia 40:161, 1999.

46. Lagae L, Buyse G, Deconinck A. Ceulemans B. Effect of levetiracetam in refractory childhood epilepsy syndromes. Eur J Pediatr Neurol 7:123-128, 2003.

47. Kossoff EH, Bergey GK, Freeman JM, et al. Levetiracetam psychosis in children with epilepsy. Epilepsia 42:1161-1163, 2001.

48. Shinnar S, Sommerville KW, Tiagabine. In: Pediatric epilepsy diagnosis and therapy (Pellock JM, Dodson WE, Bourgeois, BFD, eds), Vol 37, Ed 2, pp 489-498. New York: Demos Medical Publishing, 2001.

49. Eckardt KM, Steinhoff BJ. Nonconvulsive status epilepticus in two patients receiving tiagabine treatment. Epilepsia 39:671-674, 1998.

50. Ettinger AB, Bernal OG, Andriola MR, Bagchi S, et al. Two cases of nonconvulsive status epilepticus in association with tiagabine therapy. Epilepsia 40:1159-1162, 1999.

51. Snead OC, Depaulis A, Vergnes M, Marescaux C. Absence epilepsy: advances in experimental animal models. Adv Neurol 79: 253-278, 1999.

52. Shinnar S, Berg AT, Treiman DM, Hauser WA, Hesdorffer DC, Scakellares JC, Leppik I, Sillanpaa M, Sommerville KW. Status epilepticus and tiagabine therapy: review of safety data and epidemiologic comparisons. Epilepsia 42:372-379, 2001.

53. Krauss GL, Johnson MA, Sheth S, Miller NR. A controlled study comparing visual function in patients treated with vigabatrin and tiagabine. J Neurol Neurosurg Psychiatry 74:339-343, 2003.

54. Kalviainen R, Hache JC, Renault-Dijouadi JA. A study of visual fields in patients receiving tiagabine as monotherapy versus carbamazepine or lamotrigine monotherapy. Epilepsia 42 [Suppl 7]:256, 2001.

55. Schachter SC. Tiagabine. In: The treatment of epilepsy: principles and practice (Wyllie E, ed), Vol 65, Ed 3, pp 853-868. Philadelphia: Lippincott Williams \& Wilkins, 2001.

56. DeLorenzo RJ, Sombati S, Coulter DA, et al. Effects of topiramate on sustained repetitive firing and spontaneous recurrent seizure discharges in cultured hippocampal neurons. Epilepsia 41 [Suppl 1]:S40-S44, 2000.

57. Gibbs JW III, Sombati S, Delorenzo RJ, et al. Cellular actions of topiramate: blockade of kainite-evoked inward currents in cultured hippocampal neurons. Epilepsia 41 [Suppl]:510-516, 2000.

58. White HS, Brown SD, Woodhead JH, et al. Topiramate enhances GABA-mediated chloride flux and GABA-evoked chloride cur- rents in murine brain neurons and increases seizure threshold. Epilepsy Res 28:167-179, 1997.

59. Qian J, Noebels JL. Topiramate alters excitatory synaptic transmission in mouse hippocampus. Epilepsy Res 55:225-233, 2003.

60. Russo E, Constanti A. Topiramate hyperpolarizes and modulates the slow poststimulus AAHP of rat olfactory cortical neurons in vitro. Br J Pharmacol 1441:285-301, 2004.

61. Gryder DS, Rogawski MA. Selective antagonism of gluR5 kainatereceptor-mediated synaptic currents by topiramate in rat basolateral amygdala neurons. J Neurosci 23:7069-7074, 2003.

62. Angehagen M, Ben-Menachem E, Shank R, Ronback L, Hanson E. Topiramate modulation of kainite-induced calcium currents is inversely related to channel phosphorylation level. J Neurochem 88:320-356, 2004.

63. Elterman RD, Glauser TA, Wyllie E, et al, and the Topiramate YP Study Group. A double-blind, randomized trial of topiramate as adjunctive therapy for partial-onset seizures in children. Neurology 52:1338-1344, 1999.

64. Glauser TA, Clark PO, Strawsburg R. A pilot study of topiramate in the treatment of infantile spasms. Epilepsia 39:1324-1328, 1998.

65. Glauser TA. Topiramate in the catastrophic epilepsies of childhood. J Child Neurol 15 [Suppl 1]:S14-S21, 2000.

66. Sachdeo RC, Glauser TA, Ritter F, et al, and the Topiramate YL Study Group. A double-blind, randomized trial of topiramate in Lennox-Gastaut syndrome. Neurology 52:1882-1887, 1999.

67. Grosso S, Galimberti D, Farnetani MA, Cioni M, Mostardini R, Vivarelli R, Di Bartolo RM, Bernardoni E, Berardi R, Morgese G, Balestri P. Efficacy and safety of topiramate in infants according to epilepsy syndromes. Seizure 14:183-189, 2005.

68. Battino D, Croci D, Rossini A, et al. Topiramate pharmacokinetics in children and adults with epilepsy: a case-matched comparison based on therapeutic drug monitoring data. Clin Pharmacokinet 44:407-416, 2005.

69. Hammoudi DS, Lee SSF, Madison A, et al. Reduced visual function associated with infantile spasms in children on vigabatrin therapy. Invest Ophthamol Visual Sci 46:514-520, 2005.

70. Mackay MT, Weiss SK, Adams-Webber T, et al. Practice parameter: medical treatment of infantile spasms. Neurology 62:16681681, 2004.

71. Curatolo P, Verdecchia M, Bombardieri R. Vigabatrin for tuberous sclerosis complex. Brain Dev 23:649-653, 2001.

72. Westall CA, Logan WJ, Smith K, Buncic JR, Panton CM, Abdolell M, The Hospital for Sick Children, Toronto. Longitudinal ERG study of children on vigabatrin. Doc Ophthalmol 104:133-149, 2002.

73. Macdonald RL, Duche B. Zonisamide: mechanisms of action. In: Antiepileptic drugs. (Levy RH, Mattson RH, Meldrum BS, Perucca E, eds), Ed 5, pp 867-872. Philadelphia: Lippincott, Williams \& Wilkins, 2002.

74. Brodie MJ, Duncan R, Vespignani H, et al. Dose-dependent safety and efficacy of zonisamide: a randomized, double-blind, placebocontrolled study in patients with refractory partial seizures. Epilepsia 46:31-41, 2005.

75. Fisher RS, Kerrigan JF III, Pellock JM. Zonisamide. In: Pediatric epilepsy diagnosis and therapy, (Pellock JM, Dodson WE, Bourgeois, BFD, eds), Vol 39, Ed 2, pp 509-512. New York: Demos Medical Publishing, 2001.

76. Beghi, E. Efficacy and tolerability of the new antiepileptic drugs: comparison of two recent guidelines. Lancet Neurol 3:618-621, 2004.

77. Rogawski MA, Loscher W. The neurobiology of antiepileptic drugs. Nat Rev Neurosci 5:553-564, 2004. 